\title{
ACERVO DOCUMENTAL DO NÚCLEO DE PESQUISA PRÓ-MEMÓRIA SÃO JOSÉ DOS CAMPOS
}

\author{
Ana Carolina Alves da Silva ${ }^{1,}$ Pedro Henrique Rangel Bondezan ${ }^{2,}$ Brenda Letícia de Souza \\ Pinto $^{3}$, Gabriel Guido de Almeida ${ }^{4}$ \\ Orientação: Prof. ${ }^{a}$ Dr $^{a}$ Maria Aparecida Papali; Prof $^{a}$ Dr $^{a}$ Valéria Zanetti
}

12 - Núcleo de Pesquisa Pró-Memória São José dos Campos - Laboratório de Pesquisa e Documentação Histórica - IP\&D Univap, Av. Shishima Hifumi, no 2911, Urbanova - CEP 12244-000 -

São José dos Campos/SP.

carolinaana967@gmail.com ${ }^{1}$, pedro_bondezan@hotmail.com ${ }^{2}$, brendalsp-sjc@ hotmail.com³ ,gabrielguido.13@gmail.com papali@univap.br, vzanetti@univap.br

Resumo - Este artigo visa discorrer sobre a importância de acervos documentais que tem como objetivo a preservação, digitalização e disponibilização de arquivos históricos. Neste artigo busca-se demonstrar as possibilidades do Núcleo de Pesquisa Pró-Memória São José dos Campos, o resultado da parceria entre a Câmara Municipal da cidade, a Fundação Cultural Cassiano Ricardo e a Universidade do Vale do Paraíba (UNIVAP). Em funcionamento desde 2004, o Núcleo possui vasto acervo documental disponível em diversas plataformas, além de propiciar material para pesquisa historiográfica a respeito da história da cidade.

Palavras-chave:- História, Memória, Documentação, Acervo, Preservação.

Área do Conhecimento: Ciências Humanas

\section{Introdução}

O processo de construção do conhecimento humano, em diversos ângulos, está diretamente ligado à coleta de informações obtidas por meio de imagens, dados e documentos coletados ao longo do tempo, sendo tais informações transmitidas para a posterioridade por fontes orais ou escritas. Sendo assim, tornase relevante analisar a memória como objeto da história, para a imprescindível compreensão das construções sociais, operações ideológicas e o processo de produção de identidades, seja individual ou coletiva- (MENESES, 1992, p. 34).

O acervo documental é uma extensão dessa perspectiva de transmissão e universalização do conhecimento. Segundo Souza e Moura, esses acervos são uma opção encontrada para preservar e armazenar de forma adequada os documentos:

A construção dos acervos surge como uma alternativa para adaptar-se à necessidade de salvaguardar recordações. Eles constituem lugares para depositar o estoque material que, aos homens, é impossível lembrar por completo, pois a mente também tem os seus limites. Os materiais ali guardados podem despertar estímulos positivos no subconsciente de quem os aprecia, provocando a sensação de que muito já se superou, aprendeu e evoluiu: (SOUZA, 2010, p.4).

No Brasil, a preservação documental de acervos públicos e privados está estabelecida como uma das diretrizes que contempla o Patrimônio Cultural Brasileiro, em defesa aos bens materiais e imateriais, portadores de identidade e memória dos múltiplos grupos que compõe a sociedade brasileira, fixada pela Constituição Federal, como está previsto no Artigo 216, inserido pela Emenda Constitucional № 71, de 2012. (BRASIL, 1988):

Art. 216-A Caput: O Sistema Nacional de Cultura, organizado em regime de colaboração, de forma descentralizada e participativa, institui um processo de gestão e promoção conjunta de políticas públicas de cultura, democráticas e permanentes, pactuadas entre os entes da Federação e a sociedade, tendo por objetivo promover o desenvolvimento humano, social e econômico com pleno exercício dos direitos culturais.

XX Encontro Latino Americano de Iniciação Científica, XVI Encontro Latino Americano de Pós-Graduação e VI Encontro đ̦e Iniciação à Docência - Universidade do Vale do Paraíba. 


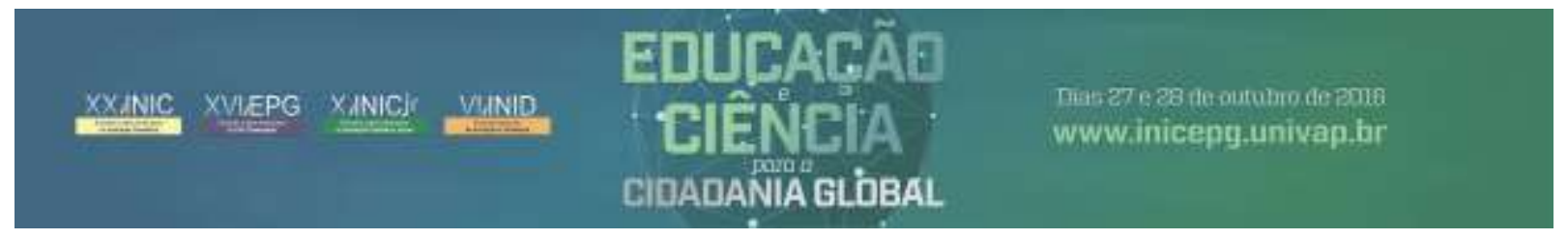

Além da Constituição vigente, outra legislação se dispõe a respeito da política de conservação de documentos de valor histórico, considerando como arquivo, os conjuntos de documentos emitidos e recebidos, desde entidades privadas até órgãos e instituições de caráter público. Desta forma ${ }_{2}$ a Lei N`8.159 de Janeiro de 1991, regulamenta como dever do Poder Público; a gestão e proteção espacial de documentos de arquivos públicos e privados, para a utilização dos mesmos como instrumento de apoio a diversos setores sociais, bem como o fomento a cultura e o desenvolvimento científico. E ainda garantindo a democratização do acesso a todos os interessados, particulares ou coletivos, em receber dos órgãos públ|cos as informações que desejarem sobre um documento, exceto nos -casos de sigilo imprescindível à intim|idade individual, a segurança da sociedade e do Estado.

(Lei N 8.159/1991, Cap. I - Disposições Gerais http://www.planalto.gov.br/ccivil_03/leis/L8159.htm).

Partindo da premissa da preservação, diversas instituições universitárias criaram centros de preservação de fontes históricas, segundo Célia Reis Camargo:

Tais centros apresentam como característica fundamental a proposta de trabalho que envolve a reunião, a preservação e a organização de arquivos e coleções (geralmente compostos de documentos originais, as "fontes primarias") e de conjuntos documentais diversos (de natureza bibliográfica ou arquivística, originais ou cópias) reunidos sob o critério do valor histórico e informativo, em torno de temas ou de períodos da historia. Trabalha-se, portanto com informação especializada_( CAMARGO, 1999: 50).

Como exemplo dessa atitude de preservação a Universidade do Vale do Paraíba - UNIVAP, localizada em São José dos Campos / SP, em convênio com a Câmara Municipal da cidade e a Fundação Cultural Cas\$iano Ricardo_,instituiu, em 02 de Março de 2004, o Núcleo de Pesquisa Pró Memoria são José dos Campos:

No dia 02 de março de 2004, foi firmado convênio entre a Câmara Municipal de São José dos Campos, a Fundação Cultural Cassiano Ricardo (FCCR) e a Fundação Valeparaibana de Ensino (FVE), mantenedora da Universidade do Vale do Paraíba (Univap).

A parceria entre as instituições visava, dentre outras coisas, promover a recuperação, a preservação e a disponibilização da história do município de São José dos Campos por meio do Núcleo de Pesquisa Pró-Memória, instituído pelo Decreto Legislativo ํㅡ 32/2003, de 02 de Outubro de 2003- (Pró Memoria - 2016).

O Núcleo de Pesquisa Pró-Memória São José dos Campos tem como sede o Laboratório de Pesquisa e Documentação Histórica, do Instituto de Pesquisa e Desenvolvimento - IP\&D, localizado no Campus Urbanova, sob a coordenação das professoras pesquisadoras $\mathrm{Dr}^{\mathrm{a}}$ Maria Aparecida Papali e $\mathrm{Dr}^{\mathrm{a}}$ Valéria Zanetti.

Em conjunto com uma equipe de estagiários, estudantes do curso de História da UNIVAP, o Núcleo de Pesфuisa -Pró - Memória vem realizando processos de conservação de documentos referentes à história da cidade desde sua fundação até os dias atuais, bem como produzindo artigos, Trabalhos de Graduação e Dissertações de Mestrado com a documentação coletada. Além disso, por meio de seu site, universaliza tal acervo ao publico em geral.

\section{Metodologia}

A pesquisa possui abordagem tanto quantitativa como qualitativa ${ }_{2}$ realizada por intermédio da discussão de bibliografia especializada em criação de acervo, preservação documental e disponibilização de documentos, em conjunto com o levantamento de todo acervo administrado pelo Núcleo de Pesquisa PróMenhória São José dos Campos - Laboratório de Pesquisa e Documentação Histórica_/IP\&D_/UNIVAP.

\section{Resultados e Discussões}

Yisando a preservação memorial da cidade e de seu passado ${ }_{2}$ o Núcleo de Pesquisa Pró-Memória São Josê dos Campos trabalha com a preservação de fontes documentais primárias, referentes ao âmbito regional e também nacional. Tais fontes são oriundas de Processos Crimes e Cíveis forenses, Atas da Câmara, bem como jornais e revistas, além de documentos públicos e privados. O Núcleo Pró-Memória também recebe -doações documentais da esfera particular, -de pessoas que veem no Núcleo um meio de preservação de fontes históricas.

XX Encontro Latino Americano de Iniciação Científica, XVI Encontro Latino Americano de Pós-Graduação e VI 2 Encontro de Iniciação à Docência - Universidade do Vale do Paraíba. 


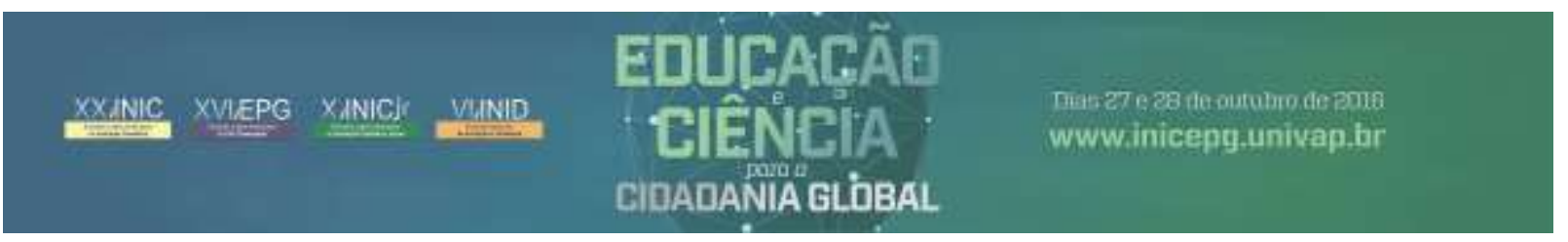

Em conjunto com instituições do poder público e privado, hoje no Núcleo de Pesquisa Pró-Memória São José dos Campos, é possível encontrar uma determinada gama de processos, jornais, livros, catálogos, reviłtas, charges, imagens, entre outros documentos, -os quais abrangem diversos períodos e refletem acontecimentos de escala nacional e global. †al acervo pode ser agrupado em três setores: material empírico, digitalizado e o disponibilizado_no site
www.camarcasjc.sp.gov.br/promemoria.

Figura 1: Acervo material do Pro memoria SJC

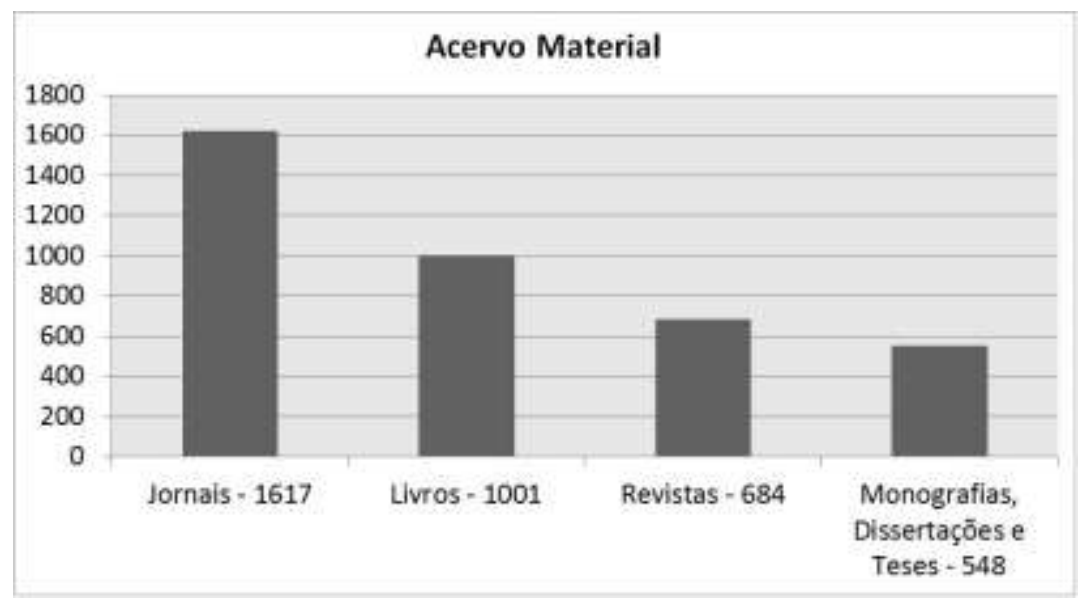

Fonte: Elaborado pelos autores.

Os documentos materiais consistem em jornais das mais diversas localidades, almanaques, livros, artigos e teses. Esses arquivos são utilizados tanto pelos professores e estagiários do Núcleo quanto pelos alunps de iniciação cientifica ou alunos do mestrado -para a produção de artigos que são publicados em anais, congressos e encontros.

Figura 2: Acervo Digitalizado do Pro memoria SJC

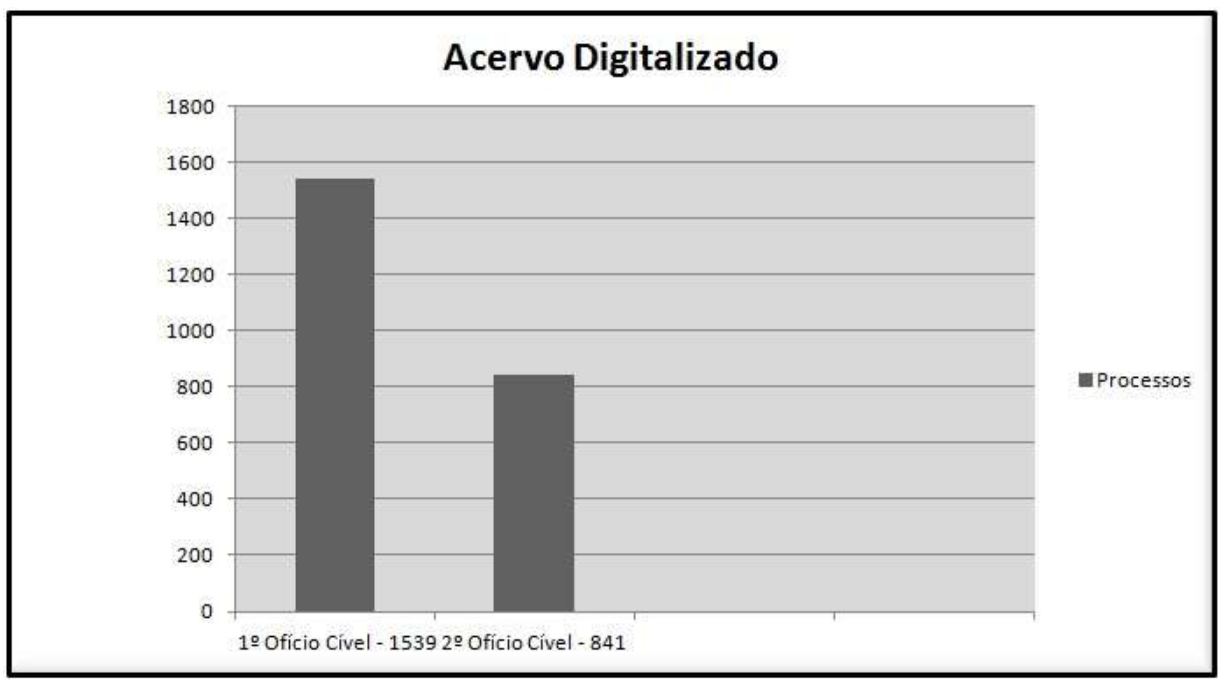

Fonte: Elaborado pelos autores.

XX Encontro Latino Americano de Iniciação Científica, XVI Encontro Latino Americano de Pós-Graduação e VI 3 Encontro de Iniciação à Docência - Universidade do Vale do Paraíba. 


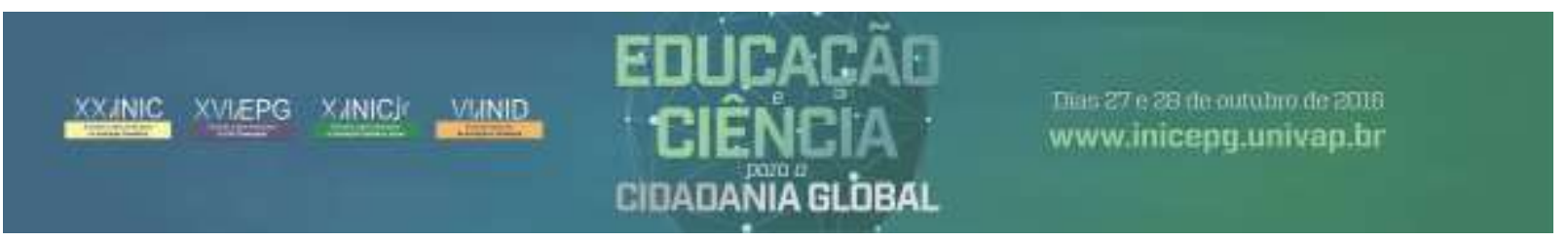

O conjunto de arquivos que compõe o acervo digitalizado é resultado de uma parceria entre o PróMemória e o Acervo Público de São José dos Campos. Os processos judiciais são cedidos pelo Acervo por um determinado período de tempo ao Núcleo de Pesquisa, onde este é responsável por digitalizá-los. Dessa forma, esses documentos ficam preservados para a posteridade, além de tornar mais simples sua disponibilização ao público.

Figura 3: Acervo Digitalizado do Pro memoria SJC

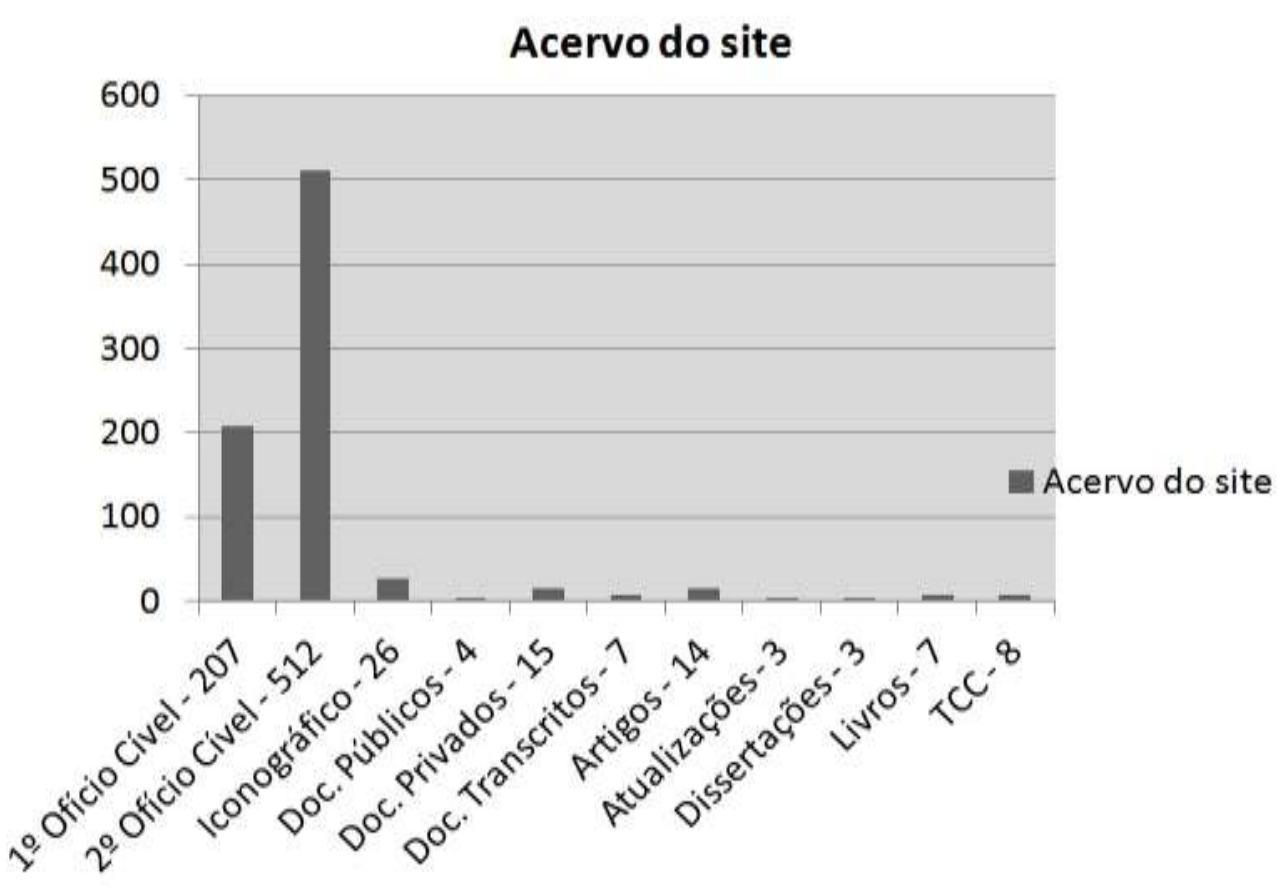

Fonte: Elaborado pelos autores.

$\oint$ acervo digitalizado do site, disponibilizado ao público, vem sendo periodicamente alimentado- pelos estagiários do Núcleo de Pesquisa Pró-Memória-, podendo ser entendido como uma síntese dos acervos anteriormente mencionados.

Todos os arquivos existentes no Núcleo servem de embasamento teórico e fontes primárias para a produção científica. Tal produção gira em torno dos temas abordados nos projetos desenvolvidos no Laboratório de Pesquisa e Documentação Histórica, sendo eles a Fase Sanatorial e o Período Pós-Abolição na cidade de São José dos Campos. O material é produzido por alunos de iniciação cientifica e os estagiários do Núcleo, sob a orientação das professoras doutoras Maria Aparecida Papali e Valéria Zanetti.

\section{Considerações Finais}

Para a preservação do patrimônio histórico documental foi de extrema importância, em se tratando do casd especifico de São Jose dos Campos, a parceria do poder público municipal com o -meio acadêmico, visando a criação e manutenção de espaços voltados a preservação da memória da cidade e da disponibilização do acervo documental para a comunidade.

O Núcleo de Pesquisa Pró-Memória São José dos Campos, fruto da ação conjunta do Poder Publico Municipal, da Fundação Cultural Cassiano Ricardo e da Universidade do Vale do Paraíba é um exemplo que, juntando esforços, podemos salvaguardar a história e a memória local, contribuindo para o entendimento que o documento não é um material bruto e objetivo, mas que exprime o poder da sociedade do passado sobre a memória e o futuro.

Os parceiros institucionais poderão, no futuro, vangloriar de seus papéis como promotores da função social da história.

XX Encontro Latino Americano de Iniciação Científica, XVI Encontro Latino Americano de Pós-Graduação e VI 4 Encontro de Iniciação à Docência - Universidade do Vale do Paraíba. 


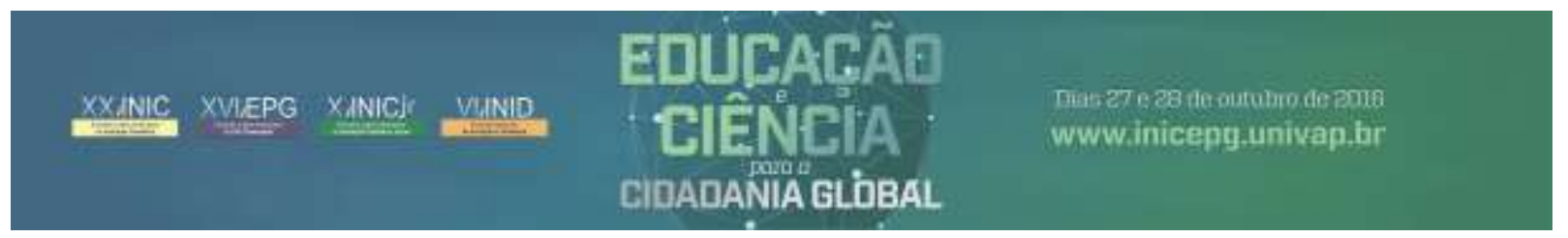

\section{Referências Bibliográficas}

CAMARGO, Célia Reis. Os Centros de Documentação das universidades tendências e perspectivas in Arquivos, patrimonio e memoria: tragetorias e perspectivas / organizadora Zélia Lopes da Silva . - São Paulo: Editora UNESP: FAPESP, 1999. - (Seminários \& Debates).

<http://www.camarasjc.sp.gov.br/promemoria/apresentacao/> Acesso em 10/08/2016 ás 15h52min.

VIANA, Juliana Eliza; SILVA, Rafael de Paula. MEMÓRIA INSTITUCIONAL E GESTÃO DOCUMENTAL: 0 CENTRO DE HISTÓRIA E MEMÓRIA DA UNIVAP/FVE (CEHVAP). XVI Encontro Latino Americano de Iniciação Científica e XII Encontro Latino Americano de Pós-Graduação - Universidade do Vale do Paraíba. 2012.

RODRIGUES, Susanne Fernandes; SILVA, Maria Helena Alves. CENTRO DE HISTÓRIA E MEMÓRIA DA UNIVAP - CEHVAP. 15 Congresso Nacional de Iniciação Científica. 2014.

BRASIL. Constituição (1988). Emenda Constitucional no 71, de 29 de novembro de 2012. As Mesas da Câmara dos Deputados e do Senado Federal, nos termos do $\S 3^{\circ}$ do art. 60 da Constituição Federal, promulgam a seguinte Emenda ao texto constitucional. In: http://www.planalto.gov.br/. Acesso em 29 de agosto de 2016 às $13 \mathrm{~h} 02$.

BRASIL. LEI № 8.159, DE 8 DE JANEIRO DE 1991. Constituição da República Federativa do Brasil. Brasília, DF, Senado, 1988. 